OPEN ACCESS

Edited by: Hasim Altan, Arkin University of Creative Arts and Design, Cyprus

Reviewed by: Marco Gola, Politecnico di Milano, Italy Boris A. Portnov, University of Haifa, Israel

*Correspondence: McCuskey Mardelle Shepley Mardelle McCuskey Shepley@ cornell.edu

tThese authors share senior authorship

Specialty section: This article was submitted to Indoor Environment, a section of the journal Frontiers in Built Environment

Received: 13 July 2021 Accepted: 03 September 2021 Published: 29 September 2021

Citation:

Shepley MM, Kolakowski H, Ziebarth N and Valenzuela-Mendoza E (2021) How COVID-19 Will Change Health, Hospitality and Senior Facility Design. Front. Built Environ. 7:740903. doi: 10.3389/fbuil.2021.740903

\section{How COVID-19 Will Change Health, Hospitality and Senior Facility Design}

\author{
McCuskey Mardelle Shepley ${ }^{*}$, Heather Kolakowski ${ }^{\dagger}$, Nicolas Ziebarth ${ }^{\dagger}$ and \\ Ellie Valenzuela-Mendoza
}

Cornell Institute for Healthy Futures, Cornell University, Ithaca, NY, United States

Background: Based on recent experiences with the COVID-19 pandemic, designers and design researchers are crafting guidelines for the development of future environments. In this context, this paper focuses on future best practices regarding environments for health, hospitality and senior care.

Methods: An extensive literature review was conducted, the results of which were distributed to a group of experts $(N=12)$ specializing in health, hospitality and design. After receiving their input, expert focus groups were conducted to further explore the proposed concepts. The document was revised based on the contributions of these field experts, resubmitted for additional input, and ultimately summarized in this paper.

Results: Based on the literature review and expert input, dozens of recommendations were made regarding post-COVID health, hospitality and seniors environments. Healthcare facilities will require additional space, access to the outdoors, service hubs, and additional infrastructure to all conversion of garages for emergency use. Hospitality settings will employ new cleaning methods, use of robotics, improved HVAC, Wellness programming, workspace options, and flexible food service operations. Senior facilities will engage more technology, socially distance visiting facilities, increase access to nature, and smaller scale residential clusters.

Discussion: By considering health and hospitality simultaneously, we come to understand the symbiotic benefits of applying goals from one sector to the other. Senior living environments are an excellent example of this approach in action. By implementing some of the proposed design recommendations generated by this research, we will be better prepared to face future challenges.

Keywords: healthcare facilities, hospitality facilities, senior facilities, post-pandemic design, COVID-19 design recommendations

\section{INTRODUCTION}

Motivated by global experiences with the COVID-19 pandemic, designers have begun to generate guidelines to steer the development of future environments. While some argue that we will eventually return to a world comparable to what we previously experienced, most believe our physical spaces should be transformed in anticipation of similar future crises (Honey-Rosés et al., 2020).

While these changes impact all building typologies, some, such as education, work, and commercial transitioned quickly to online formats. Others, such as healthcare and hospitality, were at the core maelstrom of the crisis. These two building types are particularly susceptible to major 


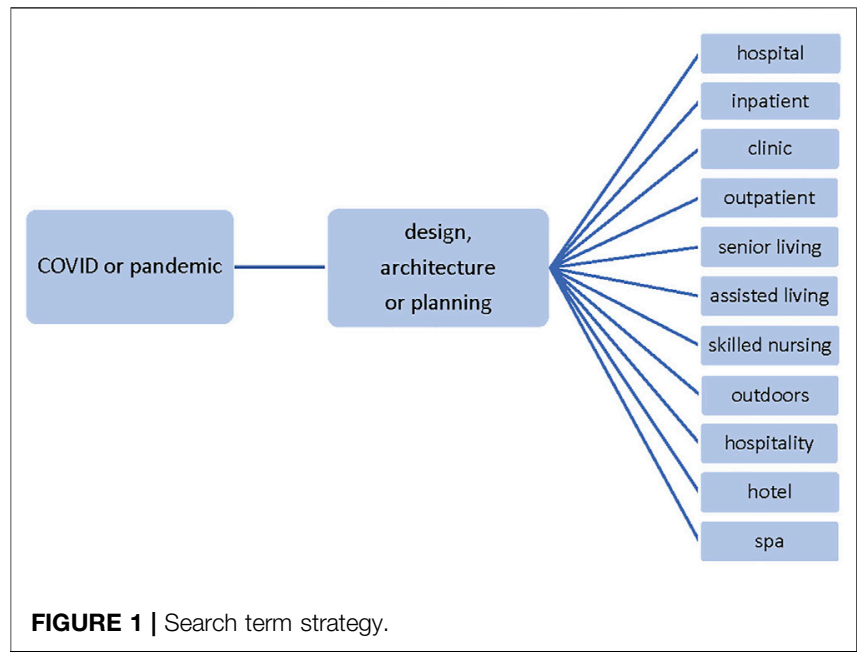

crises in health and wellness as they represent the locations for treatment (hospitals, mental health facilities, skilled, assisted and independent senior living) and restoration (hotels, gyms, food service and resorts).

This paper was initiated January 2021, as COVID-19 vaccines began to become available. Without knowing how the pandemic would play out, we began to collate the research and evidence-based predictions of industry and academic experts. The paper was not intended to be a typical systematic review as the timeframe for garnering publications was from January 2020 to June 2021 and the opportunity for researchers to analyze data and publish the results was limited. As these were not traditional times, we took a non-traditional approach. The need for information regarding both research and best practice pushed us to cast the net beyond peer-reviewed journals.

The following paper summarizes our findings.

\section{METHODS}

An extensive literature review was conducted that resulted in approximately 200 citations derived from university and online search platforms of which 41, which specifically address design, are discussed in this paper. An additional four papers were added during the review process for a total of 45. Databases that were accessed included Science Direct, JSTOR, Google Scholar, Sage Premier, American Medical Association, PubMed, Healthcare Administration, American Society for Microbiology, Academic Search Premier, Springer, and DOAJ (The search term strategy is demonstrated in Figure 1). Inclusion criteria included peer reviewed journals $(n=27)$ as well as recommendations from agencies such as the National Collaborating Center for Health, the National Investment Center, and the Substance Abuse and Mental Health Services Administration $(n=4)$. Also sought were best practice recommendations published by design and health practitioners $(n=10)$. (See Figure 2 ).

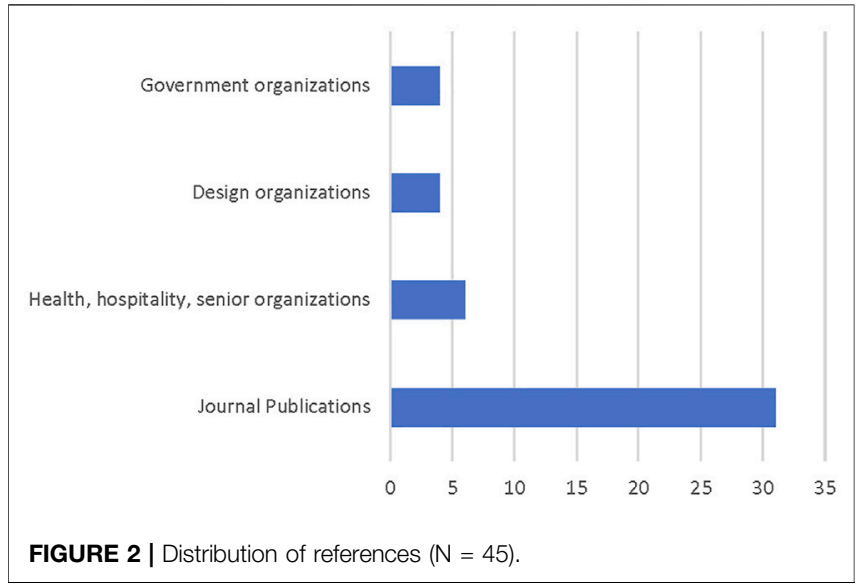

All references addressed the impact of COVID-19 on design as well as changes in policy that would result in physical environmental modifications. Due to delays in publishing and the need to bring data to the table quickly, some of the papers were in pre-release status. Publications in the lay press (e.g., The New York Times, The Wall Street Journal and the Washington Post), while insightful, were excluded.

The results were summarized in a draft document which was then distributed to a group of experts $(N=12)$ specializing in health, hospitality and design, recruited through a university industry advisory board. The organizations represented by these individuals included senior living, healthcare, hospitals, wellness providers, hospitality, architecture, mental health, and health-related finance. Each participant had more than 20 years of experience in their field and their titles included: Board of Trustees (1), CEO/President (4); Chairman (1), Partner/Principal (3), Professor of Practice (1); Executive Director (1), and COO (1).

The contribution on the part of the experts was to review the preliminary literature summary and to identify areas that were inappropriately emphasized or were missing. For example, we originally stressed the significance of technology in senior facilities without reinforcing the notion that human interaction is also critical to a good experience. As a result of this senior living expert's recommendation, we re-reviewed the content of the cited papers and uncovered statements that also supported this observation. In another case, the hospitality design expert reaffirmed our findings regarding hospitality environments, but organized it in such in a way as to emphasize the importance of essential topics. We used the tiered structure that recommended to provide an introduction to that section of the paper. In a third case, a healthcare advocate reminded us of the importance of addressing cultural differences which had been mentioned briefly, but required more emphasis.

Input was provided via written commentary and/or 30-min interviews. The revised version was then orally presented via video conference to the collective group of experts followed by discussions in two focus groups. The document was revised again based on these subsequent contributions, resubmitted for additional input, and ultimately summarized in this paper. The process is summarized in Figure 3. 


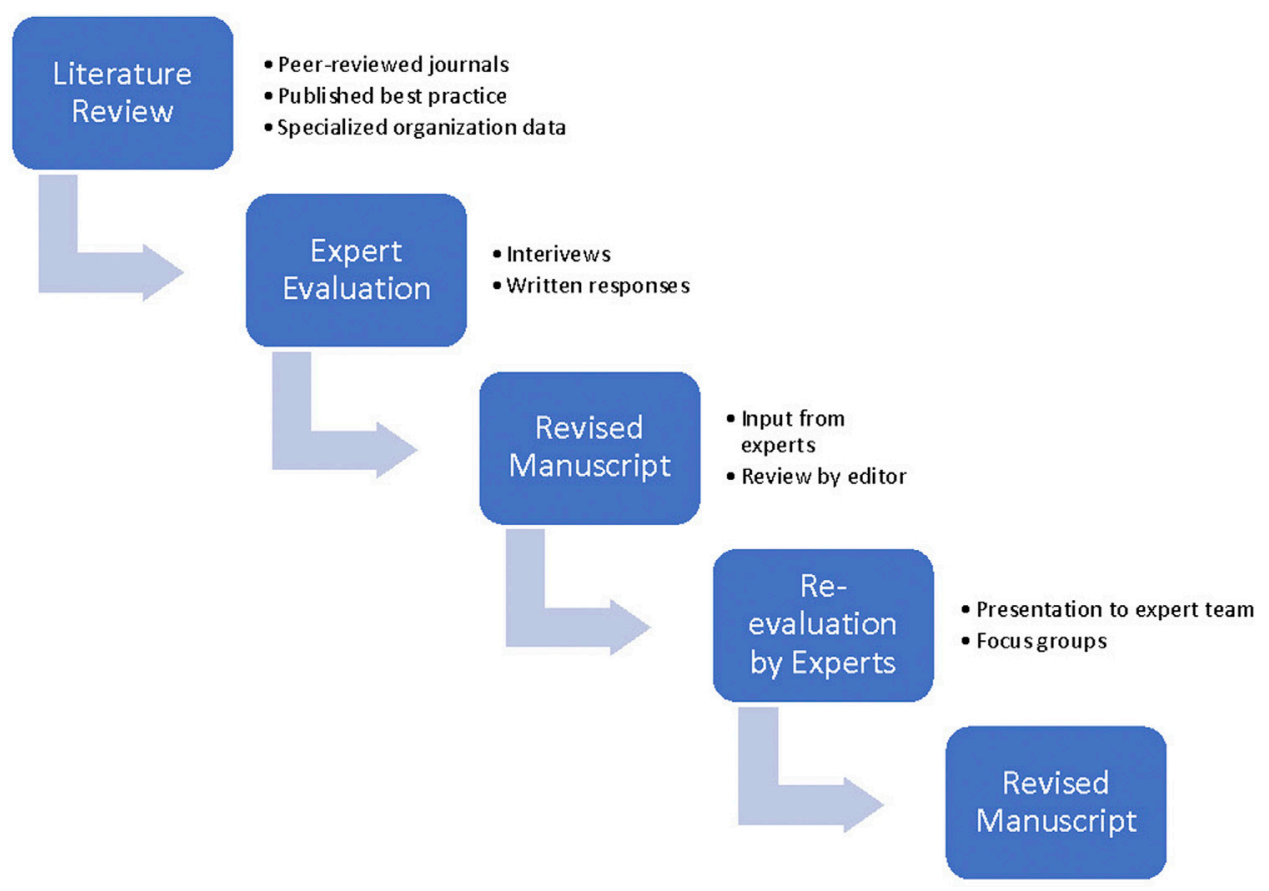

FIGURE 3 | Overall Methodology.

\section{RESULTS}

Based on the literature review and expert input, dozens of recommendations were made regarding post-COVID health, hospitality and seniors environments. Table 1 provides highlights of design strategies provided by various designers and researchers.

\section{Health and Healing Environments Inpatient Facilities}

There are multiple recommendations regarding modifications of hospitals, as they served at the epicenter of the pandemic, and had prominence in the press. The most commonly discussed measures have been improvements to the ventilation systems and the use of materials that resist bacterial and viral load (e.g., Gola et al., 2021). Schroer et al. (2021) offer six additional principles for hospital resiliency:

1. Sustain normal care operations, while addressing infectious patient needs during a pandemic.

2. Develop protocols for surge capacity.

3. Support well-being due to high levels of stress during a pandemic.

4. Isolate infectious and non-infectious patients.

5. Accommodate potential transmission risks when moving through the hospital.

6. Create spaces that allow for the transition from physical to digital care.
Broad systematic approaches have also been offered by Capolongo et al. (2020a). Based on hospital observations and input from working groups, they developed 10 strategies: separated into two tiers: design (site, typology configuration, flexibility, functional program and user-focused) and operations (healthcare network, patient safety mechanical systems and air quality, finishing materials and digital innovation).

Considerations have been raised regarding specific departments as well. Emergency rooms face particular challenges, both now (in the case of short-term resurgence) and in the future should other pandemics occur. Entry control for testing, Personal Protective Equipment (PPE) storage and disposal, cleanability, department compartmentalization, established hierarchy of zones defined by level of precaution, broadened telemedicine usage, and pre-established surge strategies are proposed of means of supporting ER functioning (HKS, 2020). Successful adaptation planning for the futureproofing of these environments should be incorporated in the asset management process to fully meet public need (Marinelli, 2020).

Butler (2020) suggests that recovery from the pandemic is an opportunity to consider reframing hospitals as centers for a wider variety of preventive/wellness services. At the same time, similar to some managed care groups and clinic systems, hospitals might provide facilities that support education and employment training. In this context, Butler (2020), suggests that postCOVID hospitals must be re-envisioned as healthcare hubs; 
TABLE 1 | Primary design strategies.

\begin{tabular}{lll}
\hline Setting & Topic Design strategies
\end{tabular}

Inpatient and

Outpatient

Additional space

Hospital and clinical hubs

Garages and parking

Mental Health

Residential

Outpatient

Outdoor spaces

Access to the outdoors

Enhanced safety

Cleaning

Hospitality

Robots

HVAC

Wellness

Workspace

Alternative uses

Food services

Dining

Buffets

Seniors

Technology

Visiting Rooms

HVAC

Site Design

Multi-cultural

Plan Configuration
Hospitals will require entry spaces for testing, storage and disposal for PPE rooms, department compartmentalization, an established hierarchy of zones defined by level of precaution, and infrastructure for broadened telemedicine use

Recovery from the pandemic could be an opportunity to consider reframing hospitals as lefts for a wider variety of preventive/wellness services and providing facilities that support education and employment training. Regarding clinical care, schools and public housing offer convenient community-based locations for health services Infrastructure needs to be planned for in-hospital parking lots and garages, such as electricity, backup generators, HVAC, oxygen, and water hookup to support field hospital setups. Patients should have access to app technology to register for visits from their cars before entering

Allow for partitioning of dayrooms, creating specialized spaces for family visits that allow for social distancing and sanitizing, signage with instructions for all, and designated spaces for isolating/observing new residents. Private rooms and single-loaded corridors are preferred

Accommodations for telemedicine and outdoor consultations

Better access to outdoor space will support stress reduction and provide venues for safe social interaction. Natural ventilation from the outside should be a design strategy to reduce infection risk

The reconfiguration of outdoor spaces to support safe social interaction on walking trails, seating areas, and participation in cultural events will aide in the transition to outdoor care activities

Hotels and spas will implement visible and improved cleaning protocols regarding products and procedures, maid service, room service and robot technology

While simultaneously maintaining "soft-touch" environments, robots will increasingly be a strategy for provision of services and infection control

Improved HVAC will include UV added to ducts, or needle point ionization, UV to wash elevator control buttons, MERV13 filters and increased outside air

Additional wellness-focused programming will support staff and guest including circadian lighting or biophiliafocused "forest bathing."

Hotel guests will remain more comfortable staying in hotels than using adjacent amenities such as outdoor bars and restaurants. The "blurring" of work boundaries will necessitate the development of adjacent spaces such as shortterm rentals and "work from hotel" options. Guestrooms may be converted to gyms, small dining areas or small meeting areas to meet social needs and enhance revenues

Accommodations for essential workers wishing to isolate from family members will be more common. Spaces should be provided for individuals recovering from COVID and needing to quarantine from family. Conversion of some hotel properties into accommodations for seniors may be desirable for assisted and independent living In-person dining will recover slowly and site design should facilitate curbside takeout. Infrastructure should continue to include technology using online ordering and contactless payments. Outdoor dining will remain more common and should be accommodated

The design of buffet bars will be modified to support infection reduction

In skilled nursing facilities, telemedicine will facilitate functions such as after-hours emergency response, evaluating changes in condition, dealing with behavior issues, medication management and prescription, identifying specialists, annual checkups, and group consultations. Independent, assisted living and skilled nursing facilities will increasingly develop programs for virtual visiting, socializing, entertainment, exercising, mealtime companionship and using voice activation to connect people via television sets. Touch-free technologies will be developed for surfaces such as sinks and doors. Facilities may specify biocidal surfaces to kill pathogens and advance cleaning

Rooms which allow residents and family visitors to be separated but visually proximate could be provided using clear interior windows to eliminate physical contact

Engineers recommend increasing use of outdoor air exchange in heating, ventilating and air conditioning systems Accessibility and the provision of amenities will be addressed at the pedestrian and city level. Appropriately sized outdoor spaces allow for social distance and positive affect

Multi-cultural needs should be addressed through the provision of spaces that support traditional activities Long double-loaded corridors where individuals are forced to spend time in public space will increasingly be avoided. We will see clearer definitions of public and private space as a tool for defining safe boundaries. Smaller neighborhoods will reduce the spread of disease by exposing fewer people during breakouts. These residential clusters have the added benefit of creating a feeling of belonging. Private rooms should be provided when feasible to support infection control stakeholders need to reassess these institutions to determine if they should remain the first stop for patients entering the healthcare system. Urban Institute scholar Howard Gleckman highlights the importance of "reconsidering the best settings for different patients" (per Butler, 2020). He notes this could mean that, in conjunction with the "appropriate infection control practices, thousands of skilled nursing homes and inpatient rehabilitation facilities could become available for patients with
COVID-19" as well as "for other patients currently being sent to hospitals" (p.1). However, there are not enough specialized professionals to staff these alternate environments and many skilled nursing facilities (SNFs) are facing financial challenges (Butler, 2020).

Facilities need flexible spaces that can adapt to new protocols for testing, treatment and vaccination and, when possible, efficient drive-thru designs that protect staff from the 
elements. Also, infrastructure needs to be planned for the inhospital parking lot and garages, such as electricity, backup generators, HVAC, oxygen, and water hookup for anticipated field hospital setups. Verderber (2021) noted major limitations to the testing and treatment environments that were created during the current pandemic including: poor patient privacy, lack of separation of symptomatic and asymptomatic individuals, limited staff and storage space, lack of daylight and positive distraction, and monochromatic environments with poor wayfinding and overcrowding.

Collectively, these recommendations will impact the design of the physical care environment by reducing the amount of time a patient spends in a healthcare facility resulting in a diminished need for waiting room spaces, necessitating the addition of spaces to access telemedicine services; these changes also create an opportunity for additional support in bolstering remote patient monitoring and the relocation of healthcare services to community settings.

\section{Outpatient Facilities}

The challenges for outpatient facilities during a pandemic are also numerous. Horner et al. (2020) offer six strategies for coping with these including: enhancing links between primary and specialty care, structured triage that prompts for tests, online patient information collection and assessment, remote appointments, group consultations and patient initiated follow ups with remote monitoring and hotlines. These recommendations have a minimal impact of the design except for the provision of and accommodation for appropriate technology infrastructure. Butler (2020) recommendations have more specific physical implications. Providing buildings that integrate clinical care, social services and housing may be a means of addressing social determinants of health. Schools might also serve as convenient community-based locations for health services. Decentralizing health services has the potential to support underserved populations in both rural areas and urban centers.

Regarding building standards, Delos (2020) has been exploring research around COVID-19 as it relates to health and wellness, which can be readily applied to outpatient and other typologies.

\section{Mental Health Facilities}

Mukhtar and Rana (2020) note that disasters have a broader impact on those with mental health challenges, which could result in a worse diagnosis. Certainly, those who are hospitalized and their families and friends are in great need of mental health services. In our research we found little information about mental health facility design during COVID19 (inpatient or outpatient), except references to greater reliance upon online counseling (D’Agostino et al., 2020; Ifdil et al., 2020; Liu et al., 2020). Many predict that the generally positive evaluation of online mental health teleservices may result in broader use in the future (Nicholas et al., 2021).

Regarding residential treatment during the pandemic, the number of individuals presenting with mental health issues increased due to the isolating and threatening impact of the virus (Loades et al., 2020; Panchal et al., 2021), but the need to maintain social distancing likely prevented services from expanding. Inpatient mental health facilities located in hospitals can use comparable strategies to standard hospital protocols as most $\mathrm{MH}$ units have comparable configurations to other types of medical units. However, free-standing $\mathrm{MH}$ facilities are not typically designed with the same infection precautions that support hospital environments (e.g., private rooms, HEPA filtered systems, cleaning protocols).

A significant debate orbits around shared versus private rooms in $\mathrm{MH}$ facilities. The latter requires a larger building footprint and therefore potentially greater construction cost and challenges to supervision, however it is perceived as less institutional and provides more opportunities for privacy and personalization. The infection control benefits of private rooms might make them even more common in the future. If sufficiently large, they can be adapted to support an additional occupant per room, which would still have more benefits than larger multi-occupant sleeping rooms. Additionally, residential mental health units that divide into smaller group clusters will reduce the frequency of interpersonal contact (as suggested below under facilities for seniors), as will avoidance of double-loaded corridors (also recommended for senior living). Consideration might be given to weather-protected, outdoor, private spaces for meetings with family and counseling.

Apart from operational protocols, Substance Abuse and Mental Health Services Administration (SAMHSA) (2020) recommends the partitioning of dayrooms, creating specialized spaces for family visits that allow for social distancing and sanitizing, signage with instructions for staff, clients and families, and designated spaces for isolating/observing new residents.

\section{Outdoor Environments}

Although outdoor environments do not traditionally fall under the heading of healthcare facilities, they do serve as healing settings. Many people have sought nature spaces for stress relief and exercise during the pandemic (Rousseau and Deschacht, 2020) and these behaviors are likely to continue into the future.

One of the main lessons of the COVID-19 pandemic is the effectiveness of outdoor social distancing on infection control (e.g., Park, Kim and Lee, 2020). Early research by Gola et al. (2021) suggests that even brief periods of access to nature by medical staff during COVID may have improved their psychophysical and mental well-being.

Regarding future public health policy, Freeman and Eykelbosh (2020) have outlined three topics that require further exploration regarding the transmission of COVID-19 in outdoor spaces, which will be pertinent again should we experience a new readily transmissible disease:

1. Definition of safe distance. Public health agencies have recommended a 6-foot distance between strangers, but this distance may have to be adjusted if research shows that it can be transmitted as an aerosol in public settings.

2. Environmental features to reduce transmission. Freeman and Eykelbosh (2020) suggest that these masks may prevent infected individuals from communicating the virus but do 
not necessarily prevent healthy people from contracting the virus through other means. Hand-washing, social distancing, and respiratory etiquette continue to be strategies to reduce transmission.

3. Survival of the virus outdoors. Current research has focused on clinical and laboratory settings but, as of this date, in-depth studies in outdoor environments have yet to be conducted.

Successfully navigating infection control in large-scale outdoor environments requires new approaches to space programming and spatial design. Natural ventilation, external space provision and its associated benefits are design strategies to reduce infection risk. Additionally, including outdoor spaces in a building project's space program will provide opportunities for physical activity and capitalize on nature's restorative effects.

In the future, more care activities in health facilities will occur in outdoor spaces, depending on climate and location. The reconfiguration of outdoor spaces to support safe social interaction on walking trails, seating areas, and participation in cultural events will aide in the transition to outdoor care activities. These design recommendations are opportunities for an affirmative health and wellness approach that will benefit both the general public, staff, and patients of healthcare facilities.

On the urban-scale, cities must be designed to reduce stress and increase healthy and positive community behaviors. What's more, studies confirm that appropriately designed urban space contributes to a reduction in violent crime (Shepley et al., 2019). As recent data has shown an increase in crime, which may be related to the stress associated with life during the pandemic, the importance of nature has become even more critical. However, the provision of new outdoor spaces must consider the potential negative impact of gentrification and its effect on adjacent land values. While greening of lots is desirable, communities must have a hand in determining the design and the retention of existing neighborhoods (Brown and Stalker, 2021). When designing outdoor space, one must take into consideration identity, the power of privilege, histories of segregation and the specific context of each community. In fact, it is critical to acknowledge that navigating outdoor spaces, for people of difference, is a potentially charged experience.

\section{HOSPITALITY SETTINGS}

Hospitality settings come with their own unique challenges. McCarthy (T. McCarthy, personal communication, March 31, 2021) notes that there are three "tiers" of responsible action:

1. Precautionary operating protocols within existing, established hospitality environments.

2. Appropriate mechanical systems in new or remodeled construction.

3. A combination of 1) and 2) with additional wellness-focused programming, including circadian lighting, or biophiliafocused "forest bathing" or other wellness related programming.
In a study by Bonfanti et al. (2021) involving interviews with hotel managers seven safety measures were identified including hygiene, work reorganization, service reorganization, technology innovations, modifications to customer wait time, staff training and improved communication. The intended outcome is improved customer safety experience. According to the recent Gensler Hospitality Pulse Survey (Hoskins and Cohen, 2021), hotel guests are more comfortable staying in hotels than using adjacent amenities such as outdoor bars and restaurants and $88 \%$ are wanting hotels to modify their services post-pandemic. Hoskins and Cohen (2021) suggest that hotels of the future will address guest needs for supporting work in multiple settings; the "blurring" of work boundaries will necessitate the development of adjacent spaces such as short-term rentals and "work from hotel" options (Hoskins and Cohen, 2021). Based on the use of hotels as healthcare delivery spaces during the COVID19 pandemic, this repurposing certainly has precedent when considering future needs. The possibility that guestrooms can be converted to gyms, small dining areas or small meeting areas will meet social needs and enhance revenues (Hoskins and Cohen 2021).

Several protocols will enhance the role of hotels in the future: room service transitioning to support healthier food options, enhanced cleanliness protocols and touch free interfaces (such as registration desks), and more thorough digital services (such as preset lighting and entertainment, and climate control) (Hoskins and Cohen 2021, Glu).

Keeping in mind the need to provide "soft-touch" in hospitality environments, the increased use of robots is a likely strategy for infection control in hotels in the future. Zhong and Verma (2019) found that guests generally rated robot-assisted services highly in a study of 88 hotels in China. Two-thirds thought of robots as a good value and would return to a hotel that employed this technology. The technology was perceived as supportive of food and other deliveries as well as check-in and check-out functions.

\section{FOOD SERVICE VENUES}

With indoor dining capacity cut during the pandemic, restaurant operators creatively expanded their outdoor dining venues to accommodate social distancing requirements. Close collaboration within municipalities to adjust the zoning requirements to use sidewalks, closed off sections of streets, or even adjacent parking lots to add tables for guests was needed. Building restaurant pods or tents to completely enclose the tables was a method some restaurants utilized but the safety of such structures is still debated.

Dining completely in the open air already has its challenges, with guest preferences regarding noise, wind, bugs, light, scents and temperature impacting their desire to remain in doors. In addition, al fresco dining creates difficulty regarding the logistics of service delivery with longer distances from kitchens, service bars and point of sale machines as well as creative adaptations for service ware and tabletop décor. Outdoor dining has severe limitations, especially in cool weather climates and seasons. 
"On average, 60.5 [Fahrenheit] is the lowest temperature diners say they'll tolerate to eat outside," according to the National Restaurant Association Household survey. Building an enclosed and temperature controlled ventilated tent can be expensive, but many guests are willing to go out to eat if social distancing measures are maintained through such a space. Will this trend continue once the pandemic fully subsides? While the zoning requirements might return to prepandemic status limiting the use of space outside the restaurant, the concept of al fresco dining will remain popular in moderate climates.

Reconfiguring restaurant dining spaces to be more flexible for guests is also a lasting impact from the pandemic. Having more flexible and moveable seating to create clusters of tables or separated sections to increase space between guests will offer more options for hotel dining. During the pandemic, some hotels converted unused guest rooms into private dining areas, as the space was available due to lower occupancy levels. While perhaps not cost effective in the long run, creative applications of unused space can allow for more flexibility in accommodating guests who are dining in the hotel.

Resourceful uses of outdoor spaces abounded throughout the pandemic, from turning balconies and courtyards into dining areas or parking lots into dining rooms, and in moderate temperature climates this approach will continue to be popular. Repurposing outdoor spaces to create al fresco kitchens can also create the enhanced perception of dining in the middle of the action and being part of the "show," while allowing for increased air flow and social distancing. Further, the popularity of the open kitchen model in many restaurants can be recreated in outdoor spaces.

One drastic change that occurred during the pandemic was the cessation of self-service buffets across all industry segments, including: retail prepared foods in grocery stores, restaurants, banquet events and gatherings to on site commercial foodservice such as hospitals and campus dining. Concerns regarding food safety and airborne pathogens made the process of self-service buffets too dangerous, and most buffets were shut down due to local food health department regulations. Often the spaces used to hold large portions of food were turned into compartments for grab-and-go meals or left bare. Modified stations where personnel would portion and package meals from a buffet, or select items for a guest behind the protection of a Plexiglas shield were utilized during the pandemic. This method of buffet service, having an employee portion and serve guests, has increased labor costs and may be unappealing to guests who are used to selecting their own food. Nonetheless, this method is a safer alternative to open-style buffets. Finally, the space dedicated to buffet style service can still be modified in multiple ways to create an attractive yet functional area for guests.

\section{SENIOR FACILITIES}

Managers of senior facilities persevered to protect their residents, while at the same time maintaining critical social links. Supporting safer environments meant a reduction in residents.
The National Investment Center found that senior housing occupancy in the United States decreased $1.3 \%$ in the fourth quarter of 2020 (National Investment Center, 2021a) and 1.8\% below that (National Investment Center, 2021b) in the first quarter of 2021. The NIC suggests that move-ins were reduced as the result of moratoriums to enhance patient safety, and moveouts were the result of transitioning to higher levels of care. Nevertheless, it is likely that the number of residents will increase post-pandemic.

The physical environments of nursing homes are generally very different than that of the preponderance of private pay senior housing (independent living, assisted living, memory care, continuing care, retirement communities) settings which are appreciably newer and feature much larger living space (Argentum, 2016). Fulmer et al. (2020) suggest that future nursing home populations might be more effectively cared for in dedicated sites such as hospice or memory programs. Longer stay patients may be better located in small facilities such as Green Houses and similar residential settings. Fulmer et al. (2020) also suggest improvements to adult day health centers which would potentially deflect residents from nursing homes. For short-stay rehabilitation, Fulmer and colleagues propose reconsideration of extended care wings in hospitals that might swing between functions but regulatory environment and payment models must change to facilitate this transition. Vipperman et al., 2021 note that recommendations for assisted living facilities and skilled nursing homes are similar, but the demands for visitation during COVID are higher and required better integration of psychosocial and medical services than has been previously offered.

At the neighborhood level, access to public transportation, amenities, and green spaces support quality of life and resilience (Sharifi and Yamagata 2018). These "will also benefit the residents and staff of nursing homes, and family members. For older people in particular, a well-designed public realm with safe, accessible, and attractive pedestrian space is linked to walkability and improved social outcomes for older adults" (Anderson et al., 2020).

The pandemic has created an opportunity to investigate physical plant innovations and flexibility in congregate living health facilities. Several recommendations have been suggested by experts as summarized in Table 2.

\section{DISCUSSION}

The authors of this paper include specialists in design, policy analysis, and hospitality. This combination of skills helped us to examine the issues from multiple perspectives. Per Capolongo and colleagues (2020a), "Even more than in the past, a multidisciplinary approach is essential, to develop systemic operational skills, capable of dealing with complexity and therefore, as a paradigm, also with the effects of the current pandemic." Through this shared lens, we have summarized the current common knowledge regarding the design of health and hospitality environments. The range of building typologies addressed were purposely selected. By sharing the tools of 
TABLE 2 | Predictions and recommendations for facilities for seniors.

\begin{tabular}{|c|c|c|}
\hline Topic & Predictions and recommendations & References \\
\hline Technology & $\begin{array}{l}\text { Technology will address touch-free mechanisms for commonly used environmental } \\
\text { interfaces such as doors and sinks }\end{array}$ & $\begin{array}{l}\text { Anderson and Holmes (2020); Hoskins and Cohen } \\
\text { (2021); Mullaney (2020) }\end{array}$ \\
\hline \multirow[t]{2}{*}{ Telemedicine } & $\begin{array}{l}\text { Telemedicine will continue to support on-call, after-hours emergency response calls, } \\
\text { evaluating changes in health conditions, managing behavior issues, medication } \\
\text { management and prescriptions, identifying specialists, annual checkups, and group } \\
\text { consultations }\end{array}$ & $\begin{array}{l}\text { American Senior Housing Association and GlenAire } \\
\text { Healthcare (2020) }\end{array}$ \\
\hline & New spaces or repurposed spaces will be provided to support telemedicine & Mullaney (2020) \\
\hline Cleanable surfaces & $\begin{array}{l}\text { Facilities will specify biocidal surfaces and materials to help kill pathogens, in addition to } \\
\text { cleaning protocols }\end{array}$ & Anderson and Holmes (2020); Vandegrift et al. (2017) \\
\hline Smart furniture & $\begin{array}{l}\text { Furniture will be specified that contributes to rapid space conversion to promote social } \\
\text { distancing }\end{array}$ & Anderson and Holmes (2020) \\
\hline Private rooms & $\begin{array}{l}\text { Private rooms [as are currently common in private pay sensor living residences], are } \\
\text { recommended rather than shared rooms to reduce contagion }\end{array}$ & Dietz et al. (2020) \\
\hline Visit rooms & $\begin{array}{l}\text { Visitor rooms which allow residents and families to be separated but visually proximate } \\
\text { could be provided using clear windows to eliminate physical contact }\end{array}$ & Andrews et al. (2014) \\
\hline Private food delivery & Individual food delivery may allow for the reduction of large dining rooms & Wu et al. (2020) \\
\hline \multirow[t]{2}{*}{ Air quality } & $\begin{array}{l}\text { Enhanced outdoor air exchange in heating, ventilating and air conditioning systems will be } \\
\text { provided }\end{array}$ & Dietz et al. (2020) \\
\hline & Improved air purification will be implemented & Mullaney, (2020) \\
\hline \multirow[t]{2}{*}{ Outdoor spaces } & More emphasis will be placed on outdoor spaces that allow for social distancing & Dietz et al. (2020); Mullaney (2020) \\
\hline & $\begin{array}{l}\text { Access to the outdoors is positively associated with the health and well-being of seniors } \\
\text { and stress reduction }\end{array}$ & Rodiek (2002) \\
\hline Neighborhoods & $\begin{array}{l}\text { Smaller residential clusters reduce the spread of disease by exposing fewer people during } \\
\text { breakouts. These residential clusters have the added benefit of creating a feeling of } \\
\text { belonging }\end{array}$ & Fong et al. (2020) \\
\hline $\begin{array}{l}\text { Clear spatial } \\
\text { definition }\end{array}$ & Territorial clarity at the site level will serve as a tool for defining safe boundaries & Hoskins and Cohen (2021) \\
\hline Race and ethnicity & $\begin{array}{l}\text { Multi-cultural needs and be addressed through the provision of spaces that support } \\
\text { traditional activities }\end{array}$ & Bookman (2008) \\
\hline Corridor design & $\begin{array}{l}\text { Double-loaded corridors, where individuals are forced to spend time in public space, will be } \\
\text { avoided when possible }\end{array}$ & Dietz et al. (2020) \\
\hline
\end{tabular}

diverse design genres, we are able to problem-solve more creatively. When considering health and hospitality specifically, we come to understand the symbiotic benefits of applying design goals from one sector to the other. Prior to developing a response to the physical environmental demands of the pandemic, researchers had found that patients prefer healthcare facilities that embrace concepts from hospitality and guests in hospitality settings often seek wellness amenities. During the pandemic and now, as we transition to a postpandemic world, these contributions and overlaps are even more clear.

\section{Health and Healing Environments}

When discussing health and healing environments, we must consider a variety of venues including inpatient, outpatient, mental health, and outdoor spaces. While each of these addresses the primary issues of infection control, their requirements are specialized. While many hospitals had policies in place for dealing with a broad health crisis, few were ready to deal with the number of patients to be housed and the demands on staffing brought on by the pandemic. Providing 24 hour treatment impacts the care environment as well as ancillary services such as food services, housekeeping and maintenance. Outpatient clinics and medical offices, in particular, were not likely to have predicted their role in treatment, testing and vaccine distribution and were likely serving as the conduit for directing patients to the appropriate healthcare services. Mental health providers sometimes found themselves serving non-compliant patients (individuals who resisted masking and social distancing), who were difficult to manage under normal circumstances and challenged by new rules. Nature became the refuge for healing (and sometimes healthcare delivery) for all of us, although it was originally unclear how effective the outdoors was regarding preventing infection transmission.

\section{Hospitality Settings}

The hospitality sector was greatly impacted as people stopped traveling and visiting spas as a means of avoiding social interaction. Multiple steps have been recommended regarding protecting guests should we experience a similar event. Apart from traditional guests, future preparation might include the provision of accommodations for essential workers wishing to isolate from family members. Additionally, individuals recovering from COVID may need rooms to quarantine from family. Potential post-pandemic strategies might focus on the conversion of some hotel properties into accommodations for seniors (Sudo, 2021). These conversions have been found to be effective in the past (Sudo, 2021) 
particularly for assisted and independent living in areas with abundant amenities.

\section{Food Service Venues}

When reopening and increasing food and beverage offerings post-COVID, there is an opportunity to reconsider the traditional food and beverage outlets. As guests have become more comfortable with to-go and contactless ordering, partnering with a local restaurant to provide room service utilizing their own menus is a cost saving measure that would also support the local foodservice eco-system (Cheng, 2020). Embracing technology through the room service delivery system, incorporating robot delivery, might also become more popular as hotel stays increase, but guests remain vigilant about social distancing.

\section{Senior Facilities}

Senior living environments serve as an excellent example of the multidisciplinary approach in action. As we discovered, health and hospitality ideas, recommended in response to the pandemic, were readily applicable to senior living and senior care. As of June 2021, there has been little peer-reviewed research published on the design of congregate living health facilities for seniors in the context of the COVID-19 pandemic; the gathering and analysis of data may take several months before it is shared with the community at large. However, as with inpatient and outpatient care, hospitality and food services, many see the challenges to senior living and care as an opportunity to improve the quality of these facilities and services.

This literature review was constrained by the lack of related peerreviewed papers due to our recent and current experience with COVID-19, but the need to get information to designers was critical.

\section{REFERENCES}

American Senior Housing Association and GlenAire Healthcare (2020). Telemedicine Transformational Innovation. Washington, DC: American Senior Housing Association

Anderson, D., and Holmes, M. (2020). How Will COVID-19 Change Healthcare Design? Design Museum Magazine. 017. Available at: https:// designmuseumfoundation.org/how-will-covid-19-change-healthcare-design/ (Accessed September 6, 2021).

Anderson, D. C., Grey, T., Kennelly, S., and O’Neill, D. (2020). Nursing Home Design and COVID-19: Balancing Infection Control, Quality of Life, and Resilience. J. Am. Med. Directors Assoc. 21 (11), 1519-1524. doi:10.1016/ j.jamda.2020.09.005

Andrews, J. R., Morrow, C., Walensky, R. P., and Wood, R. (2014). Integrating Social Contact and Environmental Data in Evaluating Tuberculosis Transmission in a South African Township. J. Infect. Dis. 210 (4), 597-603. doi:10.1093/infdis/jiu138

Argentum (2016). Getting to 2025: A Senior Living Roadmap. Available at: https://www.argentum.org/images/Argentum2025.pdf (Accessed May 25, 2021).

Bonfanti, A., Vigolo, V., and Yfantidou, G. (2021). The Impact of the Covid-19 Pandemic on Customer Experience Design: The Hotel Managers' Perspective. Int. J. Hospitality Manage. 94, 102871. doi:10.1016/j.ijhm.2021.102871

Bookman, A. (2008). Innovative Models of Aging in Place: Transforming Our Communities for an Aging Population. Community Work Fam. 11 (4), 419-438. doi:10.1080/13668800802362334

Brown, M. E., and Stalker, K. C. (2021). Assess Connect Transform in Our Neighborhood: A Framework for Engaging Community Partners in
Therefore, we also incorporated best-practice publications by health and design practitioners. Architects and designers acknowledge that, in the absence of thorough research data, the incorporation of knowledge from individuals in the field must be sought. By late 2022, the efficacy of many of the recommendations described here will be tested, and the design goals will need to be revisited. Providing good design is a reiterative process that takes place in a world which continually provides new challenges.

\section{AUTHOR CONTRIBUTIONS}

MS conceived the analysis, collected the data, contributed data, performed the analysis, and wrote the majority of the paper. HK and NZ collected the data, contributed data, performed the analysis, and wrote sections of the paper. EV-M contributed data and wrote sections of the paper.

\section{ACKNOWLEDGMENTS}

We thank Ruth Browne, Ronald McDonald House; Melissa Ceriale, Montefiore Medical; Robert Corona, Upstate Medical Center; Maria Hale, Northern Westchester Hospital; Brooke Hollis, Cornell University; Joe Jedlowski, Distinctive Living; Timothy McCarthy, Hart Howerton; Sabah Mohammed, Cornell University; Bradford Perkins, Perkins Eastman; John Rijos, Chicago Pacific Founders; Lynne Rizk, HKS; American Seniors Housing Association; and Ken Segarnick, Brandywine Living for very helpful contributions to the content of this manuscript.

Community-Based Participatory Research Designs. Action. Res. 19, 372-392. doi:10.1177/1476750318789484

Butler, S. M. (2020). After COVID-19: Thinking Differently about Running the Health Care System. JAMA Health Forum. Available at: https://jamanetwork. com/journals/jama/fullarticle/2767311 (Accessed May 20, 2021).

Capolongo, S., Gola, M., Brambilla, A., Morganti, A., Mosca, E. I., and Barach, P. (2020a). COVID-19 and Healthcare Facilities: A Decalogue of Design Strategies for Resilient Hospitals. Acta Biomed. 91 (9-S), 50-60. doi:10.23750/abm.v91i9S.10117

Capolongo, S., Rebecchi, A., Buffoli, M., Appolloni, L., Signorelli, C., Fara, G. M., et al. (2020b). COVID-19 and Cities: From Urban Health Strategies to the Pandemic challenge. A Decalogue of Public Health Opportunities. Acta Biomed. 91 (2), 13-22. doi:10.23750/abm.v91i2.951510.23750/abm.v91i2.9615

Cheng, M. (2020). Three 'New Normal' Innovations in Hotel F\&B. Hotel Executive. Available at: https://www.hotelexecutive.com/business_review/ 6716/three-new-normal-innovations-in-hotel-fb.

D’Agostino, A., Demartini, B., Cavallotti, S., and Gambini, O. (2020). Mental Health Services in Italy during the COVID-19 Outbreak. The Lancet Psychiatry 7 (5), 385-387. doi:10.1016/S2215-0366(20)30133-4

LCC Delos, L. (2020). The Delos Covid-19 Resource. Available at: https://delos. com.au/covid-19/ (Accessed September 6, 2021).

Dietz, L., Horve, P. F., Coil, D. A., Fretz, M., Eisen, J. A., and Van Den Wymelenberg, K. (2020). 2019 Novel Coronavirus (COVID-19) Pandemic: Built Environment Considerations to Reduce Transmission. Msystems 5 (2), e00245-20. doi:10.1128/msystems.00375-20

Fong, M. W., Gao, H., Wong, J. Y., Xiao, J., Shiu, E. Y. C., Ryu, S., et al. (2020). Nonpharmaceutical Measures for Pandemic Influenza in Nonhealthcare Settings-Social Distancing Measures. Emerg. Infect. Dis. 26 (5), 976-984. doi:10.3201/eid2605.190995 
Freeman, S., and Eykelbosh, A. (2020). COVID-19 and Outdoor Safety: Considerations for Use of Outdoor Recreational Spaces. National Collaborating Centre for Environmental Health. Available at: https://ncceh. $\mathrm{ca} /$ documents/guide/covid-19-and-outdoor-safety-considerations-use-outdoorrecreational-spaces (Accessed September 6, 2021).

Fulmer, T. T., Koller, C. F., and Rowe, J. W. (2020). Reimagining Nursing Homes in the Wake of COVID-19. National Academy of Medicine. Available at: https:// nam.edu/reimagining-nursing-homes-in-the-wake-of-covid-19/ (Accessed September 6, 2021).

Gola, M., Caggiano, G., De Giglio, O., Napoli, C., Diella, G., Carlucci, M., et al. (2020). SARS-CoV-2 Indoor Contamination: Considerations on Anti-COVID19 Management of Ventilation Systems, and Finishing Materials in Healthcare Facilities. Ann. Ig 33 (4), 381-392. doi:10.7416/ai.2020.2396

Gola, M., Botta, M., D'Aniello, A. L., and Capolongo, S. (2021). Influence of Nature at the Time of the Pandemic: An Experience-Based Survey at the Time of SARSCoV-2 to Demonstrate How Even a Short Break in Nature Can Reduce Stress for Healthcare Staff. Herd 14 (2), 49-65. doi:10.1177/1937586721991113

HKS (2020). ER Contagion: 8 Ways to Beat the Second Wave. Available at: https:// www.hksinc.com/how-we-think/research/er-contagion-8-ways-to-beat-thesecond-wave/ (Accessed September 6, 2021).

Honey-Rosés, J., Anguelovski, I., Chireh, V. K., Daher, C., Konijnendijk van den Bosch, C., Litt, J. S., et al. (2020). The Impact of COVID-19 on Public Space: An Early Review of the Emerging Questions - Design, Perceptions and Inequities. Cities \& Health, 1-17. doi:10.1080/23748834.2020.1780074

Horner, B., Gooch, J., and Labno, A. (2020). A Post-COVID Paradigm Shift in Outpatient Care. Boston Consulting Group. Available at: https://www.bcg.com/ publications/2020/paradigm-shift-in-outpatient-care-post-covid (Accessed September 6, 2021).

Hoskins, D., and Cohen, A. (2021). Gensler Design Forecast 2021, Reconnect: Design Strategies for a Post-COVID World. Gensler Architects. Available at: https://www.gensler.com/publications/design-forecast/reconnect (Accessed September 6, 2021).

Ifdil, I., Fadli, R. P., Suranata, K., Zola, N., and Ardi, Z. (2020). Online Mental Health Services in Indonesia during the COVID-19 Outbreak. Asian J. Psychiatry 51, 102153. doi:10.1016/j.ajp.2020.102153

Liu, S., Yang, L., Zhang, C., Xiang, Y. T., Liu, Z., Hu, S., et al. (2020). Online Mental Health Services in China during the COVID-19 Outbreak. The Lancet Psychiatry 7 (4), e17-e18. doi:10.1016/S2215-0366(20)30077-8

Loades, M. E., Chatburn, E., Higson-Sweeney, N., Reynolds, S., Shafran, R., Brigden, A., et al. (2020). Rapid Systematic Review: The Impact of Social Isolation and Loneliness on the Mental Health of Children and Adolescents in the Context of COVID-19. J. Am. Acad. Child Adolesc. Psychiatry 59, 1218-1239. doi:10.1016/j.jaac.2020.05.009

Marinelli, M. (2020). Emergency Healthcare Facilities: Managing Design in a Post Covid-19 World. IEEE Eng. Manag. Rev. 48 (4), 65-71. doi:10.1109/ emr.2020.3029850

Mukhtar, S., and Rana, W. (2020). COVID-19 and Individuals with Mental Illness in Psychiatric Facilities. Psychiatry Res. 289, 113075. doi:10.1016/ j.psychres.2020.113075

Mullaney, T. (2020). 4 Ways Covid-19 Is Shaping the Senior Living Industry of the Future. Senior Housing News. Available at: https://seniorhousingnews.com/ 2020/10/12/4-ways-covid-19-is-shaping-the-senior-living-industry-of-thefuture/ (Accessed September 6, 2021).

National Investment Center (2021a). US Housing Occupancy in Fourth Quarter Is Lowest on Record. Available at: https://www.nic.org/news-press/year/2021/ (Accessed April 8, 2021).

National Investment Center (2021b). U.S. Seniors Housing Occupancy Reaches New Low. Available at: https://www.nic.org/news-press/u-s-seniors-housingoccupancy-reaches-new-low/ (Accessed September 6, 2021).

Nicholas, J., Bell, I. H., Thompson, A., Valentine, L., Simsir, P., Sheppard, H., et al. (2021). Implementation Lessons from the Transition to Telehealth during COVID-19: A Survey of Clinicians and Young People from Youth Mental Health Services. Psychiatry Res. 299, 113848. doi:10.1016/ j.psychres.2021.113848

Panchal, N., Kamal, R., Cox, C., and Garfield, R. (2021). The Implications of COVID-19 for Mental Health and Substance Use. Kaiser Family Foundation.
Available at: https://www.kff.org/coronavirus-covid-19/issue-brief/theimplications-of-covid-19-for-mental-health-and-substance-use/ (Accessed September 6, 2021).

Rodiek, S. (2002). Influence of an Outdoor Garden on Mood and Stress in Older Persons. J. Ther. Hortic. 13 (1), 13-21.

Rousseau, S., and Deschacht, N. (2020). Public Awareness of Nature and the Environment during the COVID-19 Crisis. Environ. Resource Econ. 76, 1149-1159. doi:10.1007/s10640-020-00445-w

Schroer, J., Peavey, E., Roark, J., Holton, S., and Evans, J. (2021). The Pandemic Resilient Hospital: How Design Can Help Facilities Stay Operational and Safe. Available at: https://www.hksinc.com/our-news/articles/hks-and-arup-releasethe-pandemic-resilient-hospital/ (Accessed September 6, 2021).

Sharifi, A., and Yamagata, Y. (2018). Resilient Urban Form: A Conceptual Framework. Resilience-Oriented Urban Plann. 65, 167-179. doi:10.1007/9783-319-75798-8_9

Shepley, M., Sachs, N., Sadatsafavi, H., Fournier, C., and Peditto, K. (2019). The Impact of green Space on Violent Crime in Urban Environments: An Evidence Synthesis. Int. J. Environ. Res. Public Health 16 (24), 5119. doi:10.3390/ ijerph16245119

Substance Abuse and Mental Health Services Administration (SAMHSA) (2020). Covid19: Interim Considerations for State Psychiatric Hospitals. Available at: https://www.samhsa.gov/sites/default/files/covid19-interimconsiderations-for-state-psychiatric-hospitals.pdf (Accessed September 6, 2021).

Sudo, C. (2021). Senior Housing Adaptive Reuse Opportunities Materialize amid Hotel Distress. Senior Housing News. Available at: https://seniorhousingnews. com/2021/03/11/senior-housing-adaptive-reuse-opportunities-materialize-amidhotel-distress/ (Accessed September 6, 2021).

Vandegrift, R., Bateman, A. C., Siemens, K. N., Nguyen, M., Wilson, H. E., Green, J. L., et al. (2017). Cleanliness in Context: Reconciling hygiene with a Modern Microbial Perspective. Microbiome 5 (1), 76-12. doi:10.1186/s40168-0170294-2

Verderber, S. (2021). Pandemical Healthcare Architecture and Social Responsibility - COVID-19 and beyond. University of Toronto. Available at: https://www.daniels.utoronto.ca/pandemical-healthcarearchitecture-and-social-responsibility-covid-19-and-beyond (Accessed September 6, 2021).

Vipperman, A., Zimmerman, S., and Sloane, P. D. (2021). COVID-19 Recommendations for Assisted Living: Implications for the Future. J. Am. Med. Directors Assoc. 22, 933-938. doi:10.1016/ j.jamda.2021.02.021

Wu, P., Hao, X., Lau, E. H. Y., Wong, J. Y., Leung, K. S. M., Wu, J. T., et al. (2020). Real-Time Tentative Assessment of the Epidemiological Characteristics of Novel Coronavirus Infections in Wuhan, China, as at 22 January 2020. Eurosurveillance 25 (3), 2000044. doi:10.2807/15607917.es.2020.25.3.2000044

Zhong, L., and Verma, R. (2019). "Robot Rooms": How Guests Use and Perceive Hotel Robots. Cornell Hospitality Rep. 19 (2), 1-15.

Conflict of Interest: The authors declare that the research was conducted in the absence of any commercial or financial relationships that could be construed as a potential conflict of interest.

Publisher's Note: All claims expressed in this article are solely those of the authors and do not necessarily represent those of their affiliated organizations, or those of the publisher, the editors and the reviewers. Any product that may be evaluated in this article, or claim that may be made by its manufacturer, is not guaranteed or endorsed by the publisher.

Copyright $\odot 2021$ Shepley, Kolakowski, Ziebarth and Valenzuela-Mendoza. This is an open-access article distributed under the terms of the Creative Commons Attribution License (CC BY). The use, distribution or reproduction in other forums is permitted, provided the original author(s) and the copyright owner(s) are credited and that the original publication in this journal is cited, in accordance with accepted academic practice. No use, distribution or reproduction is permitted which does not comply with these terms. 